\title{
Optical, radar, and magnetic observations of magnetosheath plasma capture during a positive IMF $B_{z}$ impulse
}

\author{
V. Safargaleev ${ }^{1}$, A. Kozlovsky ${ }^{2,3}$, T. Sergienko ${ }^{4}$, T. K. Yeoman ${ }^{5}$, M. Uspensky ${ }^{6}$, D. M. Wright ${ }^{5}$, H. Nilsson ${ }^{4}$, \\ T. Turunen ${ }^{3}$, and A. Kotikov ${ }^{7}$ \\ ${ }^{1}$ Polar Geophysical Institute, Apatity, 184200, Russia \\ ${ }^{2}$ Department of Physical Science, University of Oulu, Oulu, 90014, Finland \\ ${ }^{3}$ Sodankylä Geophysical Observatory, Sodankylä, 99600, Finland \\ ${ }^{4}$ Swedish Institute of Space Physics, 981 28, Kiruna, Sweden \\ ${ }^{5}$ Department of Physics and Astronomy, University of Leicester, University Road, Leicester, LE1 7RH, UK \\ ${ }^{6}$ Finnish Meteorological Institute, 00101 Helsinki, Finland \\ ${ }^{7}$ Institute of Physics, St.Petersburg State University, St. Petersburg, 198504, Russia
}

Received: 7 June 2007 - Revised: 28 December 2007 - Accepted: 23 January 2008 - Published: 26 March 2008

\begin{abstract}
We present a multi-instrument study of the ionospheric response to a northward turning of the IMF. The observations were made in the near-noon (11:00 MLT) sector on Svalbard (at $75^{\circ}$ MLAT). The data set includes auroral observations, ionospheric flows obtained from the EISCAT and CUTLASS radars, the spectral width of the HF radar backscatter, particle precipitation and plasma flow data from the DMSP F13 satellite, and Pc1 frequency band pulsations observed by induction magnetometers. Careful collocation of all the observations has been made with the HF radar backscatter located by a ray-tracing procedure utilizing the elevation angle of arrival of the signals and an ionospheric plasma density profile. Prior to IMF turning northward, three auroral arcs were observed at the poleward boundary of the closed $l l b l$, inside the $l l b l$, and in the equatorward part of the $l l b l$, respectively. The northward IMF turning was accompanied by enhanced HF radar returns with a broad Doppler spectrum collocated with the arcs. The auroral arcs shifted poleward whereas the backscatter region moved in the opposite direction, which is consistent, respectively, with reconnection beyond the cusp and the capturing of magnetosheath plasma during northward IMF. Locally, magnetic noise enhancement in the Pc1 frequency band occurred simultaneously with the anomalous radar backscatter, and the absence of such signals at more remote magnetic observatories indicates a local generation of the Pc1 turbulence, which is collo-
\end{abstract}

Correspondence to: V. Safargaleev

(vladimir.safargaleev@ pgi.kolasc.net.ru) cated with the radar backscatter. Finally, we discuss possible interpretation errors which may be caused by limited observational data.

Keywords. Ionosphere (Auroral ionosphere; Particle precipitation; Plasma convection)

\section{Introduction}

The entrance into the dayside magnetosphere of new plasma, the characteristics of which are different from those of the ambient ("old") plasma, plays an important role in the magnetosphere, since it may lead to plasma instabilities. In particular, plasma detached from the plasmasphere and/or hot plasma injected from the magnetotail may stimulate geomagnetic pulsations (e.g. Kangas et al., 1998; Denton and Vetoulis, 1998). The solar wind can also be considered as a source of new plasma, which forms the low latitude boundary layer $(l l b l)$ in the dayside (Song and Russel, 1992). Instabilities in the $l l b l$ may lead to the formation of auroral arcs (Kozlovsky et al., 2003).

Theoretically, the penetration of solar wind plasma into the magnetosphere is possible by a number of different mechanisms. For example, it could occur through the development of MHD instabilities (Farrugia et al., 1998; Safargaleev and Lyatsky, 1991). However, magnetic merging at the dayside magnetopause is commonly regarded as the dominant mechanism responsible for coupling solar-wind energy and

Published by Copernicus Publications on behalf of the European Geosciences Union. 
momentum to near-Earth space. A direct penetration of the solar wind plasma through the dayside magnetopause is possible during intervals of northward interplanetary magnetic field (IMF). Here, a magnetosheath flux tube reconnects in the north and south magnetospheric lobes, beyond the cusps, where the IMF is anti-parallel to the Earth's magnetic field (Lockwood, 1998). Newly-reconnected flux tubes shorten and sink into the dayside magnetosphere. Since these tubes are filled with magnetosheath plasma, the process is referred to as magnetosheath plasma "capture" by the geomagnetic field. The concept of lobe reconnection was supported by case studies using in-situ spacecraft measurements (Onsager et al., 2001) and ground based observations (Pryse et al., 2006). The expected consequences of such plasma capture are poleward displacements of the cusp and the open/closed field line boundary (OCFLB) near noon.

Magnetopause events can be studied by low altitude spacecraft (e.g. the Defense Meteorological Satellite Program, DMSP) measuring precipitating electrons and ions (e.g. Newell and Meng, 1992), ionospheric radars measuring the convection velocity at the ionospheric footprint of the cusp (e.g. Pinnock et al., 1995), and optical instruments observing near-cusp auroras (e.g. Sandholt et al., 1986). Since Alfvénic ion cyclotron waves propagate predominantly along magnetic field lines, high-latitude dayside magnetic pulsations in the Pc1 frequency band can also be used for such studies in the cases when ionospheric propagation from lower latitudes does not take place (Safargaleev et al., 2004).

The relationship between the precipitation from nearmagnetopause magnetospheric domains and the HF radar backscatter from the ionospheric $\mathrm{F}$ region has been studied by a number of authors (e.g. Baker et al., 1995; Yeoman et al., 1997; Chisham et al., 2001, and references therein). In particular, they demonstrated that the equatorward edge of the radar backscatter with broad Doppler spectral width is coincident with the equatorward edge of the cusp particle precipitation, and the HF radar spectral width boundary (SWB) can provide a good proxy for the open-closed field line boundary (OCFLB) near noon. The relationship between optical auroras and different regimes of particle precipitation has also been a subject of many studies. The equatorward edge of the HF radar spectral width enhancement was found to be collocated with the equatorward edge of red aurora during periods of negative (southward) IMF $B_{z}$ (e.g. Moen et al., 2001), whereas during intervals of positive (northward) $B_{z}$, green auroras were related to the cusp poleward boundary (Sandholt et al., 2001).

In spite of this progress, the very limited available sets of coordinated satellite/radar/optical observations have thus far not allowed a comprehensive analysis of the magnetospheric response to IMF $B_{z}$ northward turning. For instance, the same event of 18 December 1998 was discussed from different points of view in four papers (Sandholt et al., 1999, 2000, 2001; Thorolfsson et al., 2000). In addition, the IMF $B_{z}$ component is not the only factor controlling the dayside reconnection. The ratio of IMF $B_{z} / B_{y}$ should also be taken into account (e.g. Sandholt et al., 2004; Safargaleev et al., 2004). Significant IMF variations are often accompanied by solar wind pressure (SWP) changes, which indeed occurred in the above mentioned event of 18 December 1998. The SWP variations cause deformation of the dayside magnetosphere which depends on the orientation of SWP front and may be different in different events (e.g. Kozlovsky et al., 2005). In some cases a detailed analysis cannot be achieved because of the uncertainty in the time of propagation of the disturbance from the satellite observing the solar wind to the dayside ionosphere (Milan et al., 1999).

When lacking experimental data, one tends sometimes to rely on the most widespread interpretations of the observed phenomena, ignoring other possibilities, which may lead to forming the wrong conclusions. For instance, so-called poleward moving auroral forms observed near local noon are frequently regarded as a signature of dayside reconnection. However, one should be wary of using them as an instrument for locating the cusp or OCFLB without other observations, because such auroras may occur independently of the IMF conditions (Fasel, 1995), occurring sometimes on closed magnetic field lines, and can be generated via field line resonances (Kozlovsky and Kangas, 2002) or the development of the Kelvin-Helmholtz instability (Farrugia et al., 1994). One further example lies in the interpretation of HF radar measurements. In the HF radar data, bands of high backscattered power are widely considered as a signature of the cusp and/or OCFLB (Baker et al., 1995). However, the cusp plasma is not the only source of ionospheric turbulence producing such radar backscatter. Indeed, the turbulence and hence the spectral characteristics of the returned radar signal can be affected by magnetospheric ULF waves in the Pc1-2 frequency band (Wright et al., 2004) which can be generated in many regions of the magnetosphere (Kangas et al., 1998).

Sometimes experimental data from a single instrument lead to ambiguous interpretations. For example, Sandholt et al. (2000) and Yeoman et al. (1997) interpreted the ion precipitation observed by DMSP as a signature of the cusp, whereas Newell et al. (1991) attributed such ions to the closed $l l b l$.

Thus, the present study is motivated by two reasons. Firstly, a reliable interpretation in a case study can be achieved by joint analysis of the data obtained simultaneously from different instruments in the region of interest. Secondly, the physical mechanisms acting in the dayside magnetosphere can be understood from numerous treatments of this kind. Unfortunately, such multi-instrumental studies of the dayside ionosphere are still rare.

In the present paper we analyze multi-instrument observations of the high-latitude near-noon ionosphere responding to a short-lived northward excursion of the IMF $B_{z}$ component. The data were collected during the joint Swedish (IRF, Kiruna) - Finnish (University of Oulu) - Russian (PGI, Apatity) coordinated optical and radar campaign in Spitsbergen, 
which was performed to investigate dayside auroras. In addition to the instruments traditionally used in such researches (i.e. optical instruments, ionospheric radars and DMSP satellites), data from induction magnetometers are also examined. We show that the sequence of radar, optical and magnetic events accompanying the positive $B_{z}$ excursion can be interpreted as indications of magnetosheath plasma captured into the dayside magnetosphere. A further purpose of this paper is to extend the set of IMF transition events investigated by documenting the effects occurring in the high-latitude ionosphere during a "pure magnetic" event (i.e. one with no changes in the solar wind pressure).

\section{Observations}

The following subsections describe the data used in this study, including the IMF and solar wind plasma parameters, auroras, precipitating particles, radar observations of the ionosperic plasma, and magnetic pulsations of the Pc1 frequency range. A possible scenario, which is consistent with the observations, is then discussed in Sect. 3.

\subsection{Solar wind and IMF observations}

The Geotail satellite probed the IMF and solar wind plasma in the dawnside upstream of the bow shock at $[\mathrm{X}, \mathrm{Y}$, $\mathrm{Z}]_{\mathrm{GSE}}=[14.4,-17.7,-0.5] R_{E}$. The satellite was located close to the bow shock, so that the solar wind propagation time from the satellite to the magnetopause is determined only by propagation through the magnetosheath. According to Lockwood et al. (1989), this time is calculated as:

$T_{b m} \cong 0.33 X_{m} / V_{s h}$,

where $T_{b m}$ is the propagation time between the bow shock and magnetopause, $X_{m}$ is the coordinate of the magnetopause and $V_{s h}=V_{s w} / 8$ is the average plasma flow speed in the magnetosheath. Substitution of the undisturbed solar wind velocity $V_{s w}=450 \mathrm{~km} / \mathrm{s}$ and $X_{m}=10 R_{E}$ into Eq. (1) gives $T_{b m} \approx 5 \mathrm{~min}$. Shifted by this time, the Geotail satellite data present interplanetary changes at the magnetopause. Figure 1 shows the IMF (in the GSM coordinate system) and solar wind pressure data with such a time shift. The angle between $B_{z}$ and $B_{y}$ (bottom panel in Fig. 1a) shows the orientation of the IMF vector in the $\mathrm{ZY}$ plane.

A keogram in Fig. 1a presents auroral activity from 07:45 to $08: 15 \mathrm{UT}$. There are two auroral intensification events (07:45-07:55 UT and 08:04-08:10 UT) which look like typical poleward moving auroral forms (PMAFs).

During the first event both $B_{z}$ and $B_{y}$ were near zero (the dashed line in Fig. 1a) so that $B_{x}$ was dominant. Before the positive excursion in the $B_{z}$ component (subsequently refered to as a positive impulse, PI $B_{z}$ ), the IMF vector was directed nearly along the $y$-axis, i.e. perpendicular to the magnetic field lines at the near-noon magnetopause. Just at the

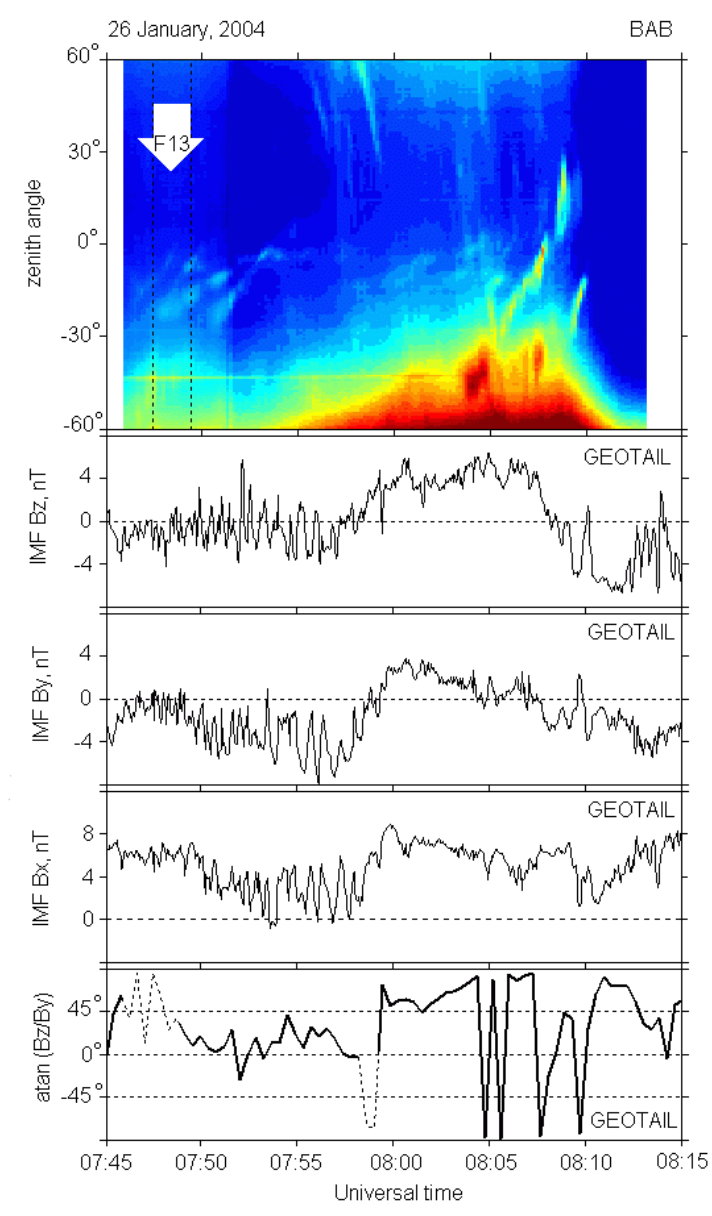

a

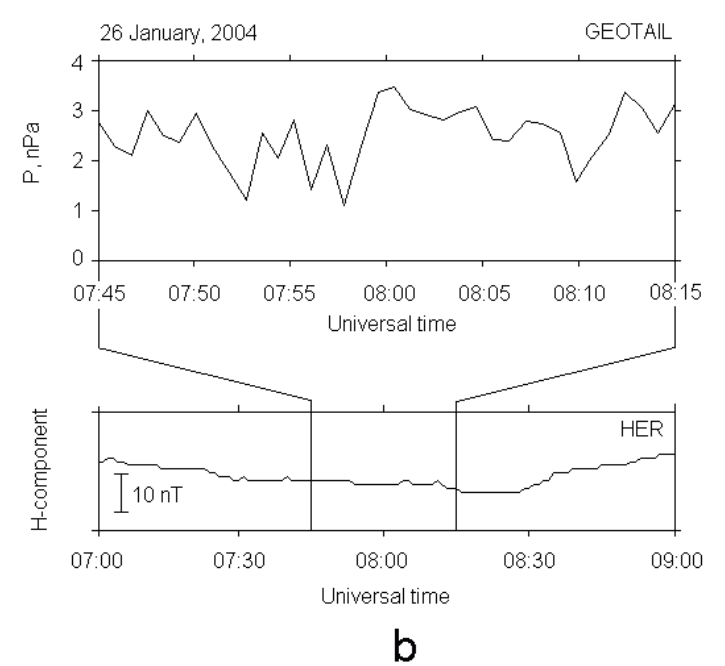

Fig. 1. Auroral activity above the BAB (top panel) and the conditions in interplanetary medium as measured by the Geotail satellite. The white arrow indicates the time of DMSP F13's passage through the TV camera field of view. The bottom panel shows the magnetic variations at the low-latitude Hermanus observatory. 


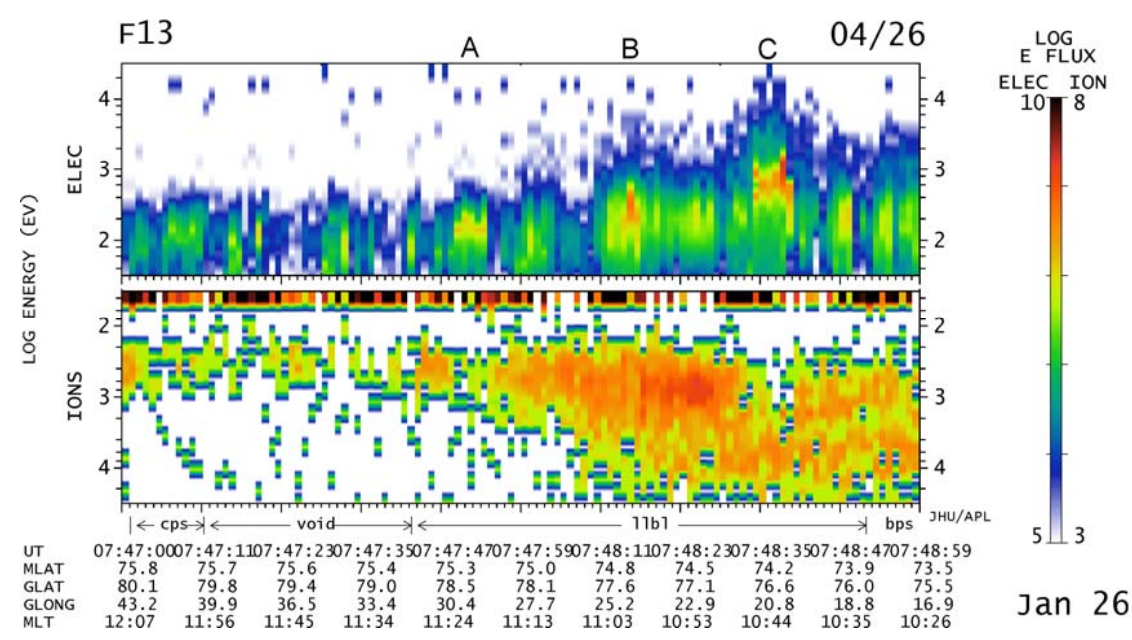

(a)
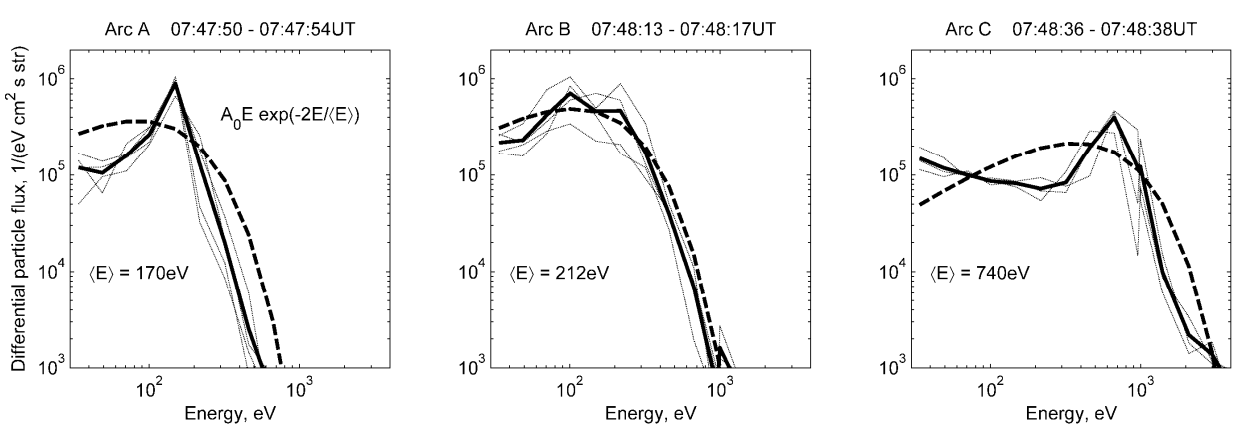

(b)

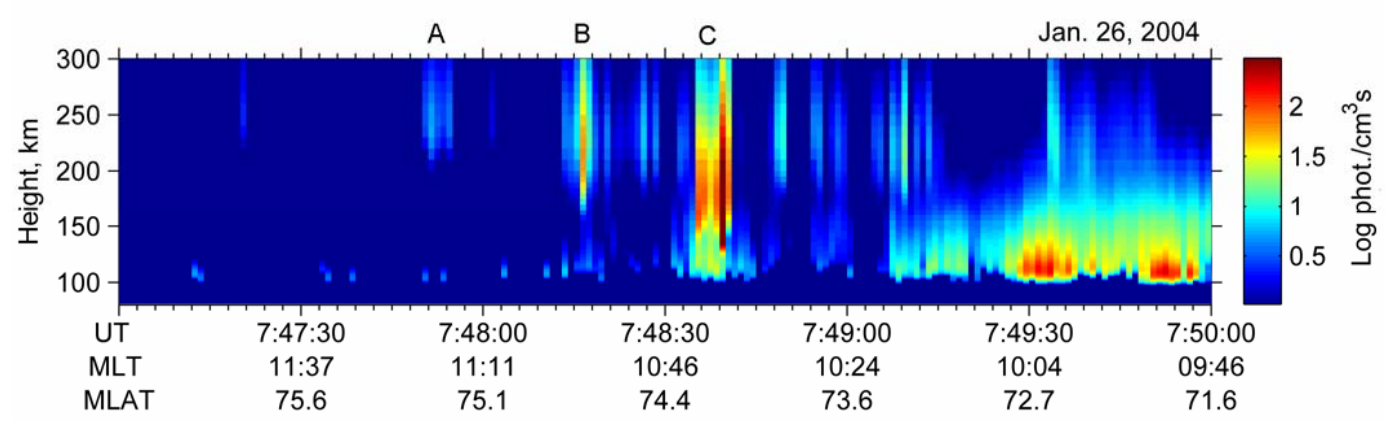

(c)

Fig. 2. (a) Distribution of precipitating particles above the region of interest measured by the DMSP F13 satellite; (b) spectra of precipitating electrons in structures A, B and C inferred from DMSP data (bold solid and thin dotted lines) and corresponding Maxwellian spectra (bold dashed lines); (c) altitude profile of the associated auroral luminosity.

beginning of the second PMAF event the IMF turned northward, so that during this event the IMF vector was mostly in the $\mathrm{XZ}$ plane. This may result in the magnetosheath plasma being captured via the reconnection of magnetosheath fluxtubes beyond the northern and southern cusps (Song and Russel, 1992). The two auroral events are next considered in more detail. For the first event, the locations of auro- ras with respect to magnetospheric domains are studied by DMSP data. For the second event, we study the correlation of the auroras with IMF variations and enhancements in HF radar backscatter.

As mentioned above, in many cases IMF changes are associated with those in SWP, which complicates the interpretation. Fortunately, in the events studied here, SWP changes 
can be neglected, which is demonstrated in Fig. 1b. The top and bottom panels in this figure show the SWP variations observed by the Geotail satellite and a magnetogram from the low-latitude observatory at Hermanus (HER; $34.4^{\circ} \mathrm{S}$, $19.2^{\circ} \mathrm{E}$ ), respectively. The magnetic measurements near the equator can be used to detect compressions of the magnetosphere which are displayed there as step-like increases in the $\mathrm{H}$-component. Figure $1 \mathrm{~b}$ shows no appreciable variations either in space or on the ground. This means that the events studied here are associated with a "pure magnetic" impact.

\subsection{Optical and DMSP measurements prior to a positive $B_{z}$ impulse}

In this section we focus on the faint multiple arcs that occurred ten minutes prior to the PI $B_{z}$ event. During the occurrence of these arcs, the DMSP F13 satellite was passing through the TV camera field of view. Precipitation data from the satellite make it possible to determine the position of the arcs with respect to the open/closed magnetic field line boundary.

Optical observations were made by the all-sky TV-camera in the Barentsburg observatory $\left(\mathrm{BAB} ; 78.05^{\circ} \mathrm{N}, 14.12^{\circ} \mathrm{E}\right.$, in the Spitsbergen archipelago). The corrected geomagnetic latitude (MLAT) of the camera is $75.2^{\circ}$, with local magnetic noon being at about 08:52 UT (MLT $\approx \mathrm{UT}+3 \mathrm{~h})$. This camera provides high-resolution optical observations of auroras in white light. The keogram on the upper panel in Fig. 1 shows the dynamics of the auroras at the geomagnetic meridian of the observatory. The open arrow and vertical dashed line indicate the interval of DMSP F13 passage through the TV camera field of view. The interval is characterized by the brightening and poleward displacement of faint auroral arcs which is not associated with significant changes in the solar wind parameters.

The top panel in Fig. 2 shows spectrograms of the electron and ion precipitation measured by the DMSP satellite. Herein, the boundaries of magnetospheric domains are identified by the dayside automated region identification program (Newell et al., 1991). It is seen that the satellite crossed three structures in electron precipitation (indicated by letters A, B and $\mathrm{C}$ on the top of Fig. 2) which might be signatures of three auroral arcs. All the structures are embedded in the low latitude boundary layer, $l l b l$. The energy of electrons forming the structures increases toward the lower latitudes (i.e. from A to C). Structures $\mathrm{A}$ and $\mathrm{C}$ are associated with gaps in the low-energy $(<1000 \mathrm{eV})$ ion precipitation.

Bold lines in Fig. $2 b$ present averaged spectra of precipitating electrons in structures A, B, and C calculated from the DMSP data. The dashed lines show Maxwellian spectra corresponding to the mean energy of the electrons in these structures. It is seen that the spectra corresponding to structures A and $\mathrm{C}$ differ from Maxwellian ones. They have clear peaks at energies $150 \mathrm{eV}$ and $650 \mathrm{eV}$, respectively. These peaks and the above-mentioned gaps in ion precipitation indicate field-aligned potential drops (an upward field-aligned electric field) above the satellite which accelerates precipitating electrons and suppresses the ion precipitation. The potential drops in structures A and C may be associated with upward field-aligned currents at the poleward and equatorward boundaries of the $l l b l$, respectively. The electron spectrum of structure B is Maxwellian, which indicates that the electrons here do not undergo field-aligned acceleration.

The spectra of precipitating electrons can be used to estimate the heights of the associated auroras. Using the model by Sergienko and Ivanov (1993) and the DMSP data, we have calculated the altitude distribution of luminosity for the interval considered, which is presented in the lower panel in Fig. 2. It is seen that the electrons precipitating in structures $\mathrm{A}, \mathrm{B}$, and $\mathrm{C}$ produce maxima in auroral luminosity at altitudes of $260 \mathrm{~km}, 220 \mathrm{~km}$, and $160 \mathrm{~km}$, respectively.

The three auroral frames in Fig. 3 correspond to the moments when the F13 satellite was observing structures A, B, and $\mathrm{C}$. Geographic north is on the top and geographic east is on the right side of the images. The bright area in the southeast is due to sunlight. The satellite trajectories shown on the frames are mapped along magnetic field lines to the calculated auroral altitudes of the corresponding structures (i.e. 260, 220, and $160 \mathrm{~km}$ ). Crosses show the positions of the satellite at the moments of the frames (indicated at the top right corner of each frame). It is seen that the electron precipitation structures A, B, and C correspond to optical auroral arcs intersected by the satellite. These arcs are indicated by corresponding letters on the frames.

The fragments of the satellite trajectory are shown by different colors indicating different regimes of precipitation, which correspond to the spectrogram in Fig. 2a. From 07:47:44 to $07: 48: 51 \mathrm{UT}$, the satellite passed through the closed $l l b l$ (green fragment). The red vectors originating from the trajectory represent the plasma velocity component perpendicular to the trajectory, obtained from the plasma drift meter onboard the satellite. At about 07:47:50 UT, just after entrance into the $l l b l, \mathrm{~F} 13$ observed a velocity shear, which signifies a sheet of upward field-aligned current. This current is collocated with the arc A. One more prominent signature of upward field-aligned current was observed at about 07:48:40 UT, which corresponds to the arc C.

The central $\operatorname{arc}(\operatorname{arc} \mathrm{B})$ is located in the region of enhanced anti-sunward convection inside the $l l b l$. In contrast to the arcs $\mathrm{A}$ and $\mathrm{C}$, the $\operatorname{arc} \mathrm{B}$ is not associated with a noticeable velocity shear, consistent with a low intensity of the arc-associated FAC. The dynamics of this arc are also different from that of the $\operatorname{arcs} \mathrm{A}$ and $\mathrm{C}$. Namely, the arc B moved poleward, while the $\operatorname{arcs} \mathrm{A}$ and $\mathrm{C}$ did not change their positions. The $\operatorname{arc} \mathrm{B}$ was moving northward within the region between the poleward boundary of high-energy ion precipitation (indicated by $\operatorname{arc} \mathrm{C}$ ) and the poleward boundary of the $l l b l$ (indicated by arc A). As it travelled northward, the arc B reached the poleward arc $\mathrm{A}$ and then disappeared. After that, a new arc appeared at the latitude where "old" arc B originated. 

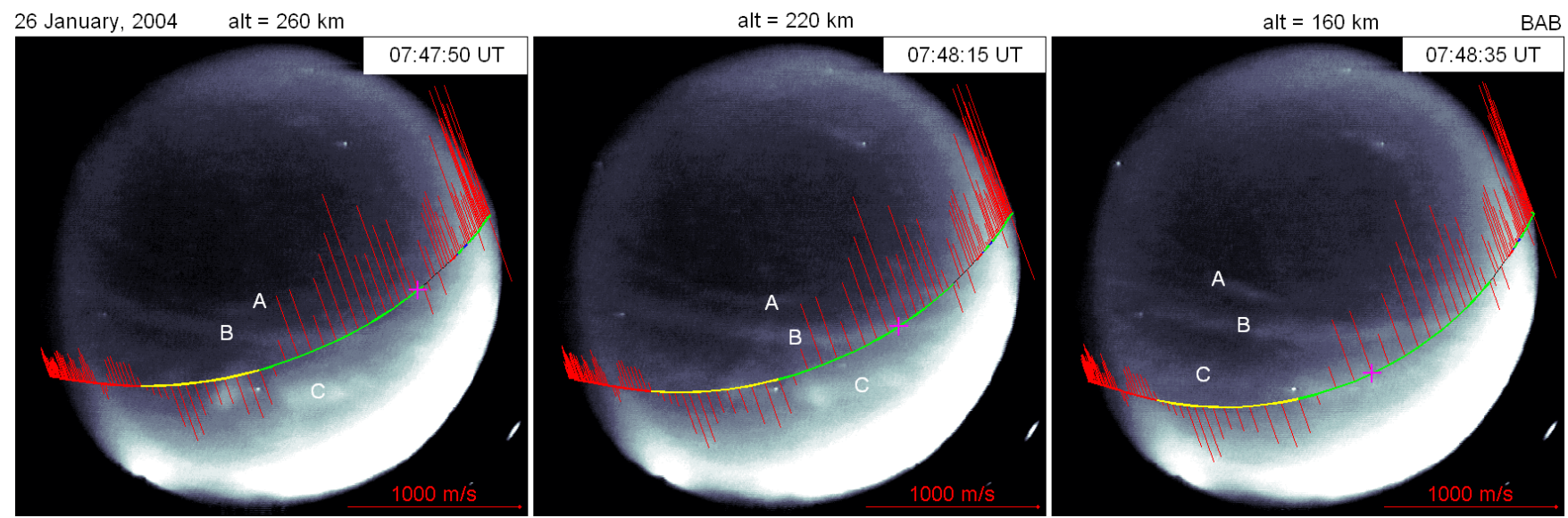

Fig. 3. The DMSP trajectory mapped on the TV frames. The cross shows the DMSP position at the moment indicated on each frame. The green fragment corresponds to $l l b l$, the yellow fragment is bps. Red arrows are the components of plasma velocity perpendicular to the DMSP trajectory. Arcs A, B and C correspond to the structures A, B and C in precipitating particles shown in Fig. 2. North (geographic) is on the top of each frame, west is on the left. The specious white area in the south-east is sunlight.

Thus, the optical data combined with DMSP measurements show that a few minutes before the IMF $B_{z}$ turned northward, i.e. before the PI $B_{z}$, the source of central arc B was located inside the $l l b l$, on closed magnetic field lines. At the same time, the arc A was collocated with the poleward boundary of the $l l b l$, and the source of arc $\mathrm{C}$ was located in the vicinity of the llbl/bps boundary. In Sect. 3, we will use these findings to locate the ionospheric projection of the $l l b l$.

\subsection{Coordinated radar and optical measurements during the PI $B_{z}$ event}

The ionospheric convection velocities presented in this section were measured by the European incoherent scatter (EISCAT) Svalbard radar (ESR) and the SuperDARN (Chisham et al., 2007) HF radar in Hankasalmi (HANK). The HANK radar is one of the two radars forming the CUTLASS bistatic HF radar system. The signals returned to the HF radars have undergone a Bragg-like backscattering process from fieldaligned electron density irregularities in the ionosphere. The CUTLASS data used in the present study have a range resolution of $45 \mathrm{~km}$ (with the first range starting at $180 \mathrm{~km}$ from the radar). The HANK scan sector is shown in Fig. 4a by grey shading, the bold solid line indicates beam 9 of the radar, and the darker area shows the field of view of TV camera in Barentsburg. The ESR-32m antenna was pointed to the west at $45^{\circ}$ elevation, which allowed us to measure the ionospheric plasma flow along the East-West direction in the F-region (above $200 \mathrm{~km}$ ). The beam of the ESR is shown by the bold dashed line in Fig. 4a. Panel (b) in Fig. 4 shows the location of the auroras with respect to both radar beams.

Figure 5a shows a spatial distribution (in the geomagnetic coordinate system) of the spectral width of return signals observed by the HANK radar during a series of six scans from
08:00 to $08: 15 \mathrm{UT}$. In this figure one can see a region of ionospheric irregularities which looks like a patch of large spectral width radar returns. The patch appeared at 08:03 UT near the noon meridian (east of Spitsbergen, $\sim 120^{\circ} \mathrm{E}$ ), then moved dawnwards (westwards) at a constant geomagnetic latitude. At 08:12 UT it reached $\sim 92^{\circ} \mathrm{E}$, and after that it disappeared. The propagation velocity of the western edge of the irregularities is about $1500 \mathrm{~m} / \mathrm{s}$. The appearance of the irregularityies follows the positive IMF $B_{z}$ excursion with a delay time of $\sim 5 \mathrm{~min}$. Note, that this time is twice the Alfvén travel time from the magnetopause to the ionosphere as estimated by Freeman et al. (1990).

Time series plots in Fig. 5b show the passage of the irregularities through beam 9 of the HANK radar. This beam crosses Spitsbergen slightly toward the east of the zenith of the TV camera in BAB (see Fig. 4). These data have a temporal resolution of $3 \mathrm{~s}$. The focus here is the patch observed after 08:05 UT (the extended line of backscatter before this time is ground scatter from behind the radar). The passage of the irregularities is accompanied by an enhancement in all measured parameters (i.e. power, line-of-sight velocity, and spectral width). The slope of the enhancement in the plots is caused by a tilt of the edge of the irregularities relative to the radar beam rather than a poleward propagation. Vertical solid lines indicate the interval of positive (northward) IMF $B_{z}$.

The keogram in Fig. 6a indicates the dynamics of the second PMAF event that occurred simultaneously with the ionospheric irregularity enhancements observed by the HANK radar. The letters on the keogram mark the positions of the $\operatorname{arcs} \mathrm{A}, \mathrm{B}$, and $\mathrm{C}$, which have been traced in the TV data subsequent to the first PMAF event. Note that between the enhancements near 07:50 UT and 08:05 UT the most poleward arc A looked like a series of very faint patches distributed 
in latitude. This feature hindered the identification of the arc on the keogram constructed along a fixed meridian, and we have had to highlight the trace of its lower edge with the upper green curve in Fig. 6a. The arc $\mathrm{C}$ was rather bright but also inhomogeneous, and at the beginning of the second PMAF event could be confused on the keogram with central $\operatorname{arc~B.~So,~we~have~also~highlighted~its~movement~with~}$ a green curve. Subsequently these highlighted arcs are used for tracing the position of the ionospheric projection of the llbl.

Between the first PMAF event at 07:48 until about 08:04 UT, the location of the $l l b l$ boundary indicated by arc A did not change. The second PMAF event started at 08:04 UT as an enhancement of the arc C. One minute later the arc $\mathrm{B}$ enhanced. After that, all three arcs started moving poleward, which signifies a shift of the $l l b l$ projection to higher latitudes. To highlight the motion of $\operatorname{arcs} \mathrm{A}$ and $\mathrm{C}$, their equatorward edges are indicated by green curves on the keogram.

The observed poleward shift of the $l l b l$ boundary is consistent with the Combined Precipitation and Convection Model by Newell et al. (2004). Indeed, this statistical model shows that for northward IMF in the pre-noon MLT sector the $l l b l$ is thicker and its poleward boundary is located at higher latitude than for southward IMF. The position of the $l l b l$ might also be dependent on the solar wind pressure, however, in the event considered the SWP was essentially steady.

To understand the origin of the ionospheric irregularities observed by the HF radar, it is important to know the location of the backscatter with respect to the auroral arcs. Commonly, the echo locations are based on a simple rangefinding algorithm assuming straight-line propagation to a virtual height of $400 \mathrm{~km}$, with the velocity of light in vacuum. Actually, due to the fact that the ionosphere is a dispersive medium, a signal propagates along its specific ray path with a group velocity. As a result, the distance to where the echo originates can be smaller that predicted by the standard algorithm. In Figs. 5b and 6 a correction is included based upon a ray-tracing estimate (Villain et al., 1984) for this particular case. The basic parameters in estimating the group delay definition were the measured elevation angles of the 11.2MHz HANK echoes $\left(\sim 12^{\circ}\right)$ and the TRO dynasonde F-layer electron density of about $1.4 \times 10^{11} \mathrm{~m}^{-3}$. (Non-calibrated F-layer electron density measurements from the ESR radar were half this value, probably due to snow in the antenna dish. No data were available from the Svalbard ionosonde). We found that a Pedersen ray trajectory with $\sim 9^{\circ}$ elevation angle can form direct, half-hop F-layer backscatter at the altitude of $\sim 300 \mathrm{~km}$ if the model layer has its electron density close to $\sim 1.4 \times 10^{11} \mathrm{~m}^{-3}$. Note that the raytracing in this case actually gives a result close to the standard SuperDARN rangefinding.

The top panel in Fig. 7 presents the keogram along beam 9 of the HANK radar (this beam is shown on the TV frame in Fig. 4b by the yellow curve). The geographic latitude of the auroras is calculated for the height of luminosity equal
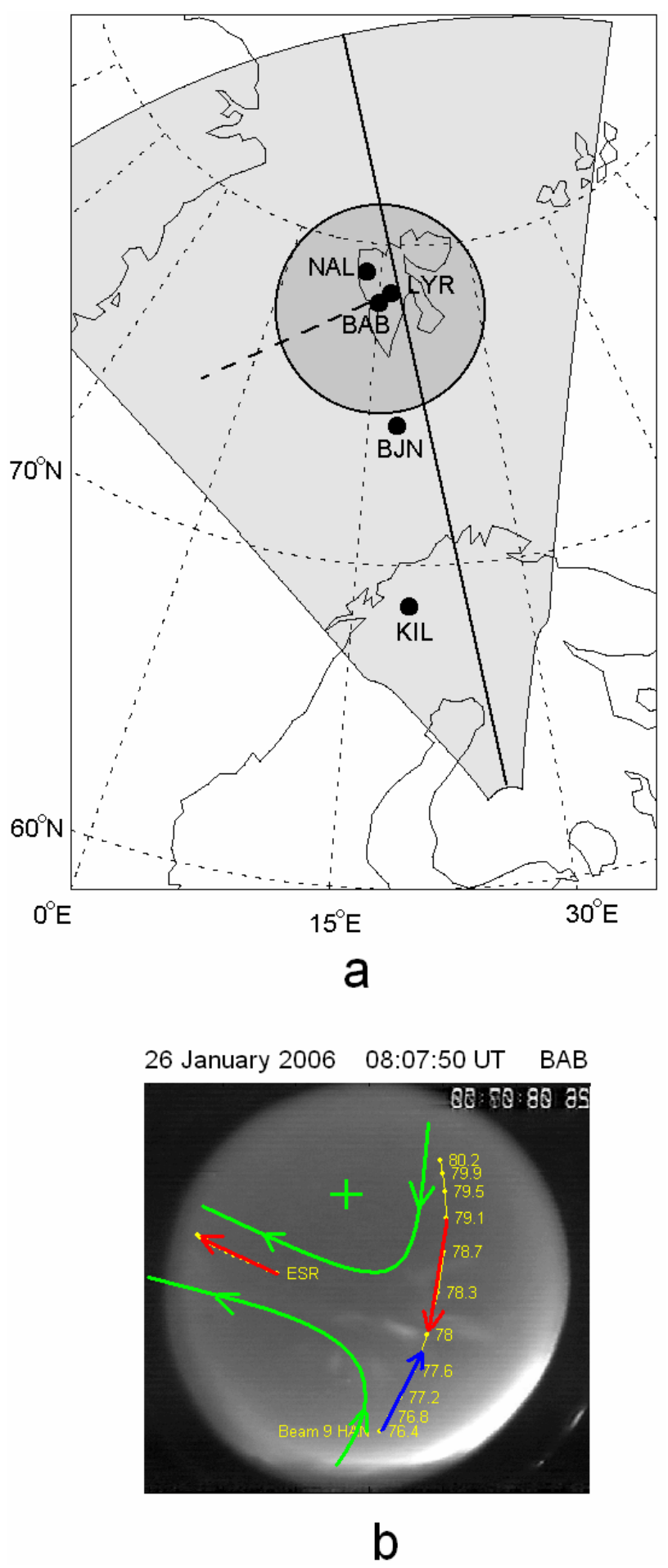

Fig. 4. (a) Location of the instruments in the region of observations; (b) optical auroras and ionospheric convection model (green curves) inferred from EISCAT and CUTLASS measurements shown with red and blue arrows. The green cross is the supposed position of the focus of the high latitude reverse cell. 


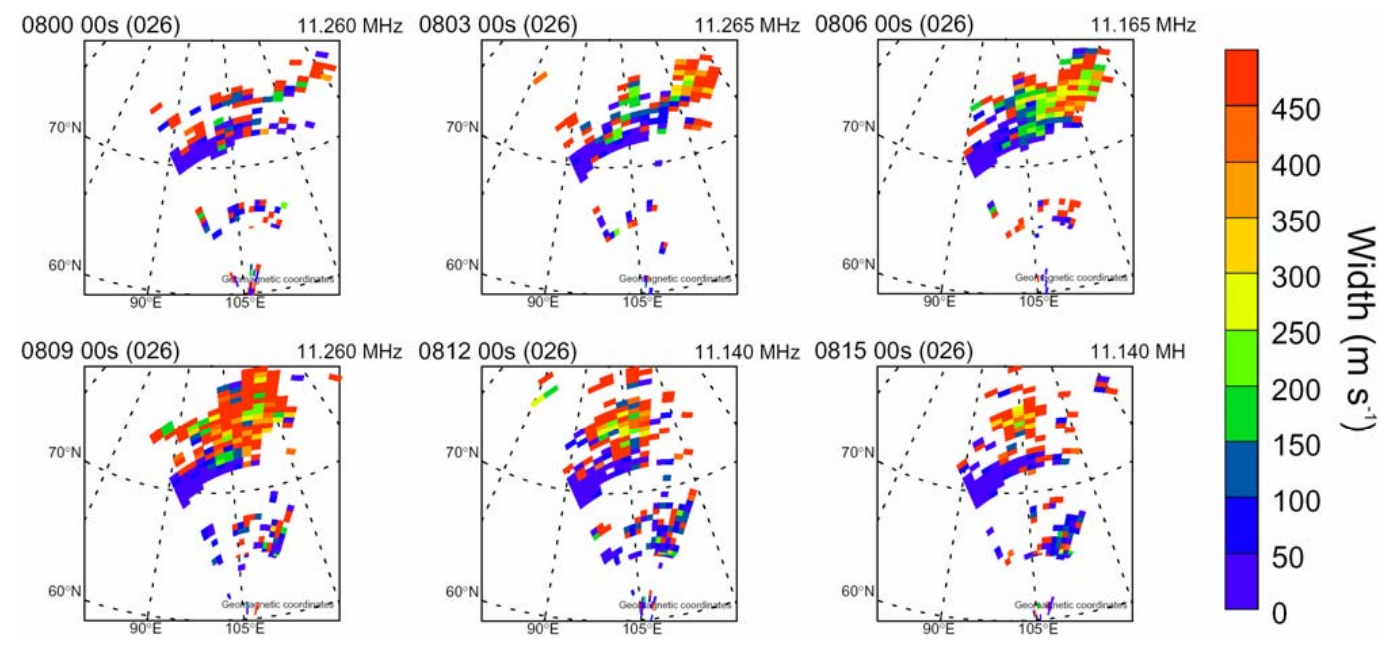

(a)
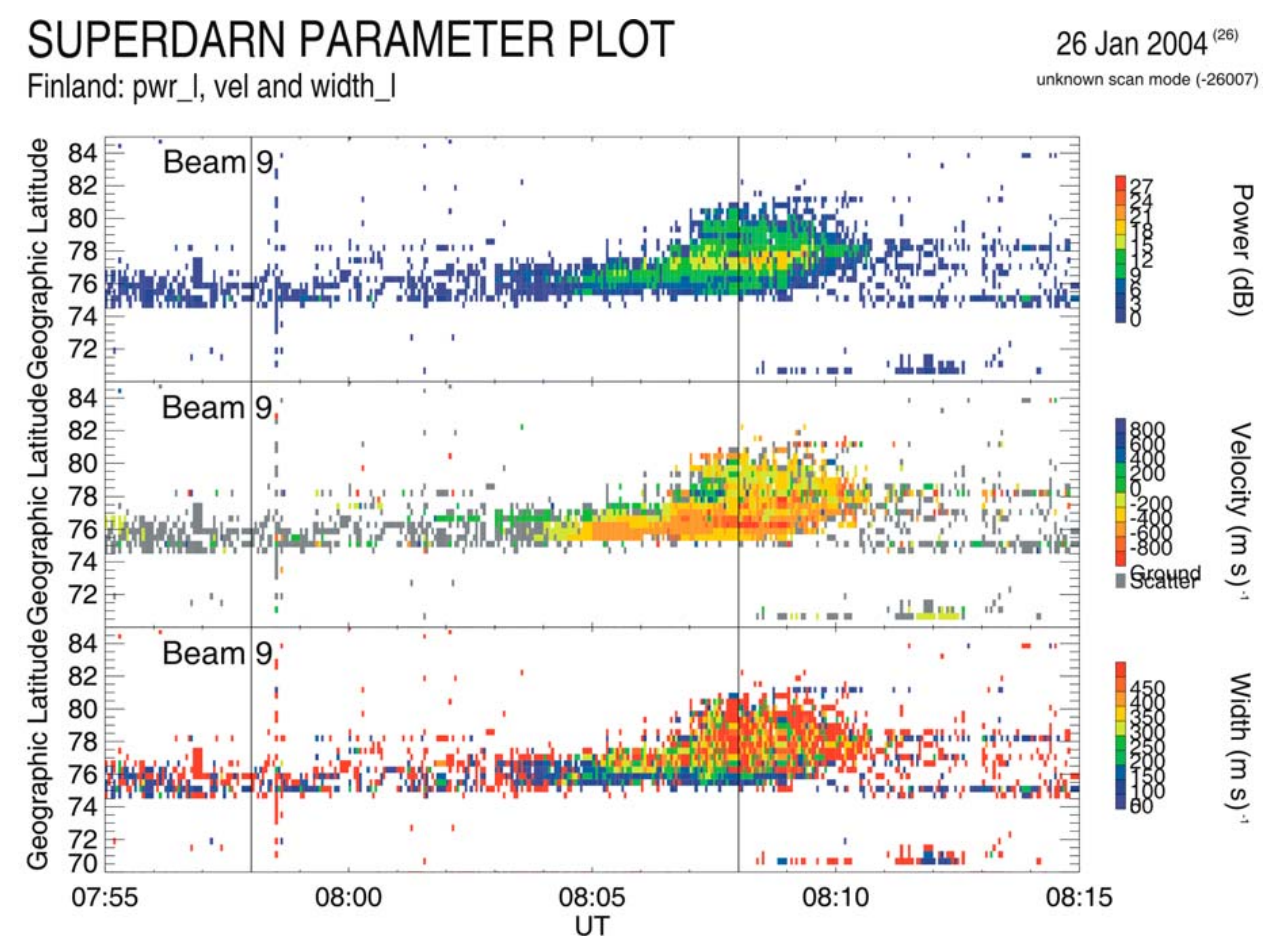

(b)

Fig. 5. (a) Passage of ionospheric irregularities through the CUTLASS field of view (b) Data from beam 9 of the radar. The interval of positive $B_{z}$ is indicated with vertical lines.

to $220 \mathrm{~km}$, which corresponds to the intermediate arc B. The other two panels in Fig. 7 show the 1-o-s velocity and the spectral width of the scattered signals observed along beam 9. The latitude of the backscatter is determined by the ray-tracing procedure described above. The radar measurements are projected along the magnetic field lines to a height of $220 \mathrm{~km}$ and presented in the same time interval and latitude range as the keogram. The positions of the $\operatorname{arcs} \mathrm{A}, \mathrm{B}$, and $\mathrm{C}$ are indicated on the radar data plots by black lines with corresponding letters.

From the first and second panels in Fig. 7, one can see that the poleward displacement of the auroras starts at about 
08:05 UT, and at the same time the region of broad spectral width backscatter is detected by the radar. This backscatter region is located between the arcs $\mathrm{A}$ and $\mathrm{C}$, which are coincident with its poleward and equatorward edges, respectively. The arc B is located in the center of the broad spectral width backscatter region. The poleward motion of the $\operatorname{arcs} \mathrm{A}$ and $\mathrm{B}$ corresponds well with the poleward expansion of the broad spectral width backscatter.

The bottom panel in Fig. 7 presents the 1-o-s velocity of the ionospheric plasma. The highest flow velocity is observed at 08:07-08:08 UT. In the poleward part of the backscatter region (poleward of arc B), the line-of-sight plasma flow is directed to the south (toward the radar), whereas southward of $\operatorname{arc} \mathrm{B}$ the flow is to the north. These plasma flows are sketched on the auroral frame in Fig. $4 \mathrm{~b}$ above. The red and blue arrows along beam 9 show the south- and northward 1o-s velocity in the vicinity of the arc B seen at $78^{\circ}$ latitude. The red arrow in the west (left part of the frame) represents the westward 1-o-s velocity observed by the ESR radar at that time. Combination of the observed 1-o-s velocities suggests a signature of two convection cells, which is depicted by the green curves in Fig. 4b. The arc B, located between the cells, separates the regions of the clockwise and counterclockwise flows in the north and south, respectively.

\subsection{Magnetic response on the ground}

In Fig. 8 the CUTLASS spectral width data are presented together with the data of two induction magnetometers located in BAB in Spitsbergen, and KIL in the northern Scandinavia (see the map in Fig. 4a). The vertical line at about 08:04 UT on the CUTLASS plot indicates the beginning of the broad spectral width backscatter event. At the same time, a sharp enhancement in the broadband $(0.1-2.0 \mathrm{~Hz})$ magnetic noise was observed by the induction magnetometer at $\mathrm{BAB}$ (middle panel in Fig. 8). However, this magnetic disturbance was not observed to the south or to the south-east of BAB at the Scandinavian array of induction magnetometers (see, e.g. KIL data presented in the bottom panel in Fig. 8) or the Russian station Lovozero on the Kola Peninsula located $\sim 600 \mathrm{~km}$ eastward of KIL. This indicates that the magnetic noise originated from a spatially restricted area of the ionosphere at latitudes higher than, at least, $70^{\circ} \mathrm{N}$, which could presumably be collocated with the region of the broad spectral width radar backscatter.

Commonly, magnetic pulsations in the $0.1-2.0 \mathrm{~Hz}$ frequency band are associated with the electromagnetic ioncyclotron instability of an anisotropic plasma. In the case under study, such anisotropic plasma could originate in the magnetosheath during the course of reconnection (Anderson and Fuselier, 1993). Earlier, such a mechanism for highlatitude Pc1s was suggested by Cole et al. (1982). Then, more recently, André et al. (2000) and Wright et al. (2004) showed that the Pc1/2 turbulence can be a reason for spectral width enhancement in CUTLASS data. Indeed, our data

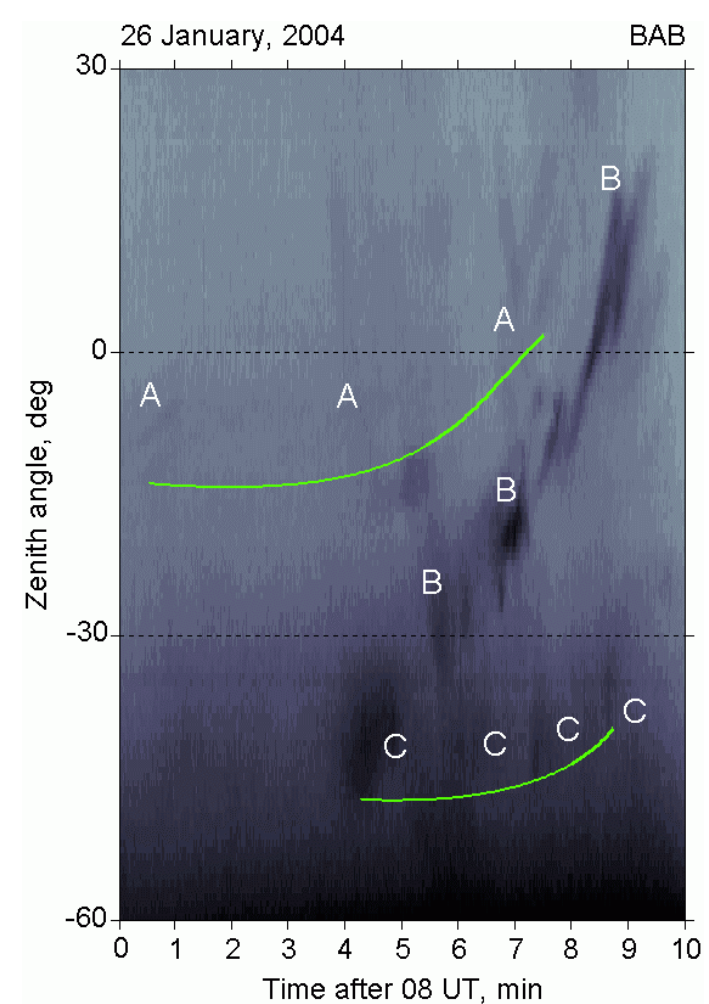

a

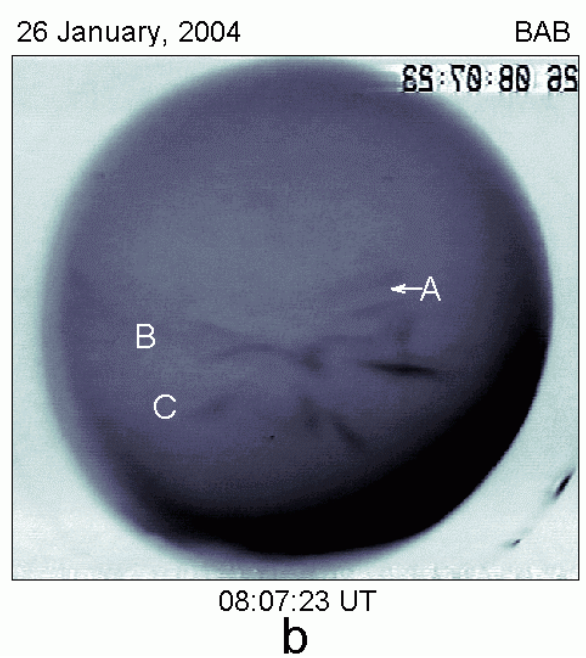

Fig. 6. Response of arc system A, B and C to the positive $B_{z}$ impulse: (a) keogram showing the arc dynamics and (b) arc system as seen by the TV camera in Barentsburg. The green line on the keogram highlights the trace of the movement of the lower edge of the $\operatorname{arcs} \mathrm{A}$ and $\mathrm{C}$.

support the connection between the magnetic pulsations and the radar backscatter event. 

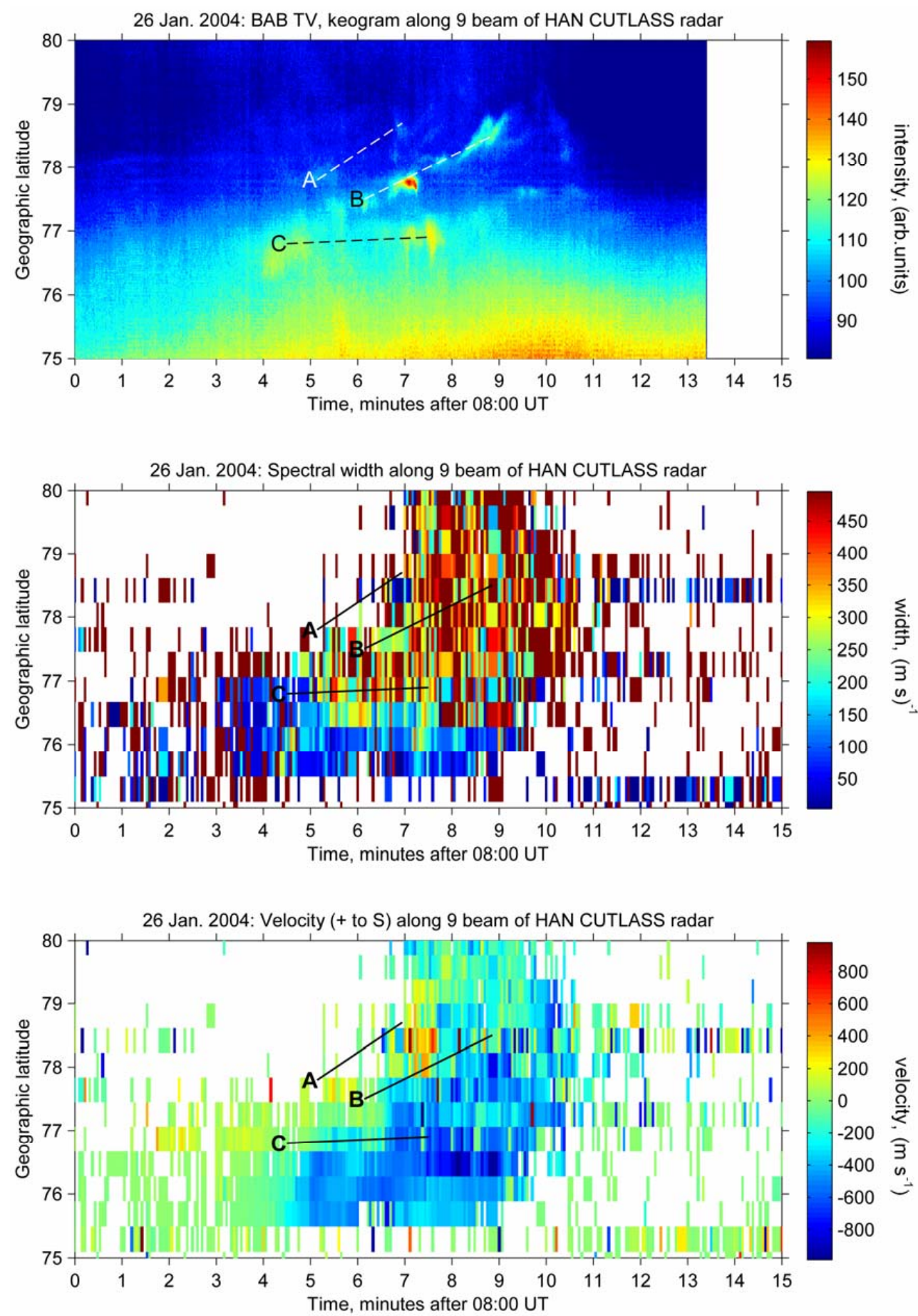

Fig. 7. Location of the ionospheric irregularities with respect to the auroral arcs A, B and C. The velocity scale here is reversed with respect to that in Fig. 5.

\section{Discussion}

\subsection{On the accuracy of the observations}

The high-latitude dayside ionosphere is a "screen" where magnetopause events are displayed. Hence, ground-based observations in this region allow for the investigation of the magnetopause phenomena. However, in practice, the interpretation of such observations encounters some difficulties, which are discussed below. 

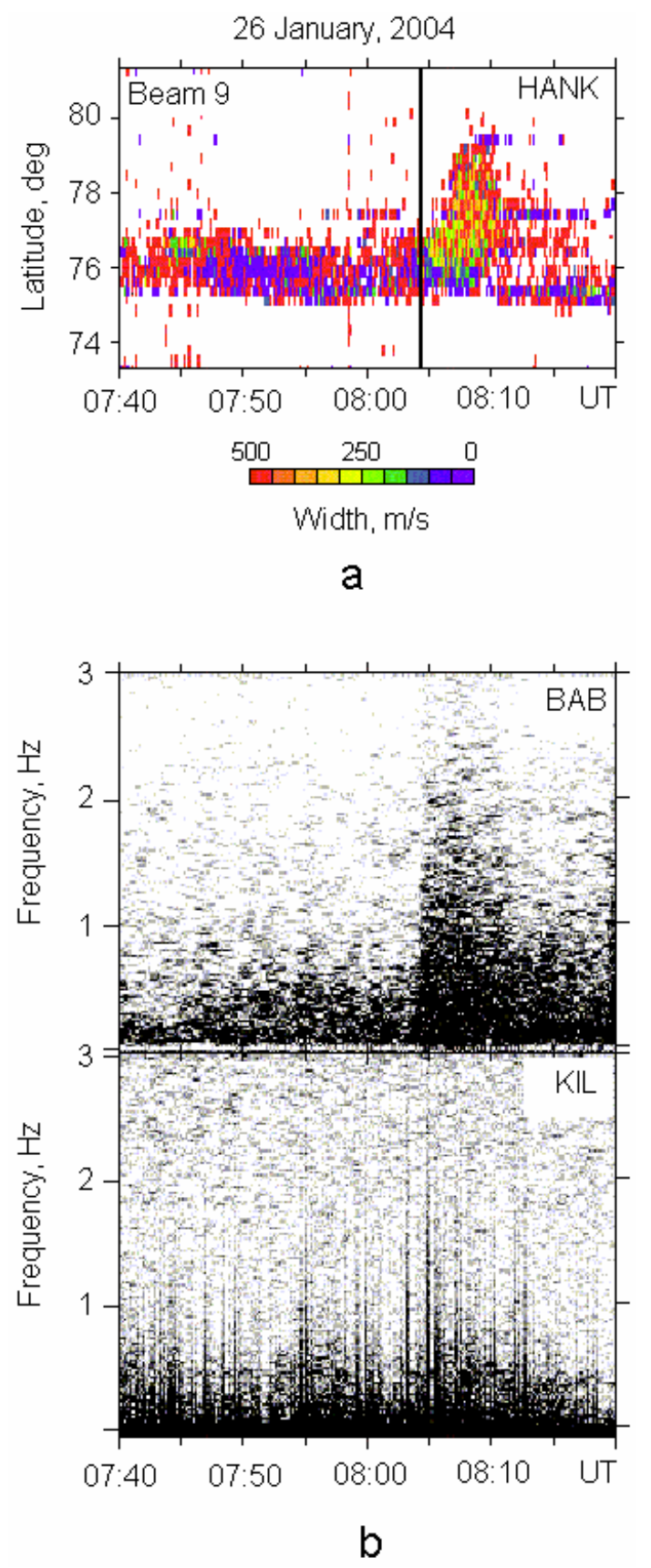

Fig. 8. (a) Appearance of ionospheric irregularities in CUTLASS and (b) induction magnetometer data. The locations of magnetometers BAB and KIL are shown in Fig. 4a.

Using the database of DMSP satellites, Newell and Meng (1992) have demonstrated that the high-latitude dayside ionosphere is connected with four different magnetospheric plasma domains: mantle, cusp, low latitude boundary layer, $l l b l$, and boundary plasma sheet, bps. The ionospheric footprints of these regions are rather narrow in latitude, especially around noon where the magnetosphere is strongly compressed by the solar wind. The small dimensions make

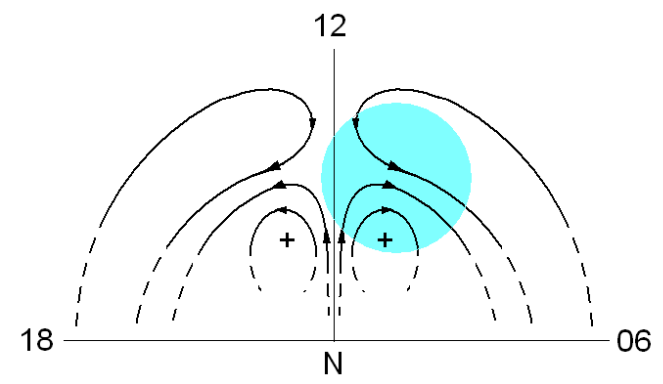

a

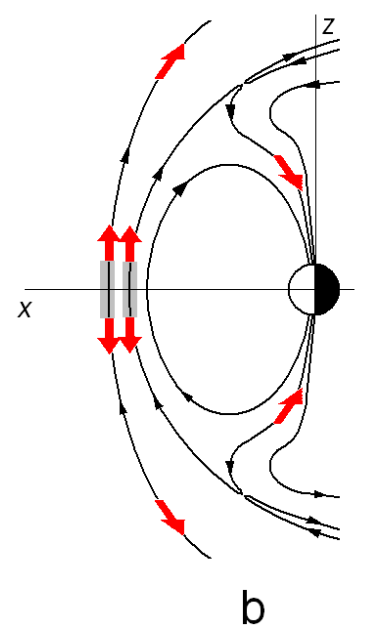

Fig. 9. Sketches showing the main features of reconnection under negative IMF $B_{z}$ : (a) four-cell convection pattern in the ionosphere; (b) capturing of anisotropic plasma from the magnetosheath and penetration of magnetosheath $\mathrm{Pc} 1 \mathrm{~s}$ to the near-cusp ionosphere. The green circle indicates the field of view of TV camera in Barentsburg; grey areas are magnetosheath ions; red arrows show the propagation of the EMIC waves.

the identification of the magnetospheric domains associated with observed ionospheric phenomena difficult, which sometimes leads to ambiguity in the interpretation of the observations.

In studying solar wind-magnetosphere interaction it is important to monitor interplanetary parameters just near the dayside magnetopause, which requires an inclusion of the time of propagation of the disturbance from the satellite probing the interplanetary medium, to the bowshock, and the transition time through the magnetosheath. However, the satellites are usually located far away from the Earth. The uncertainty in the propagation time that stems from variability of the interplanetary medium as well as from any separation of the satellite location and the Sun-Earth line, may reach 20 min (Ridley, 2000).

A correspondence between changes in the solar wind and ionospheric effects can be easily revealed for sharp isolated interplanetary disturbances. However, such events are rare. 
Moreover, in many isolated events, both the IMF and solar wind pressure change simultaneously, which leads to a coupling of the effects of reconnection and magnetospheric compression (Sandholt et al., 1999; Kozlovsky et al., 2005).

Undoubtedly, multi-instrument measurements provide more information, which enables a more certain interpretation of observations. However, so far the number of coordinated multi-instrument studies in the dayside ionosphere is not large enough, so that the results obtained in this way are not statistically verified. Therefore, multi-instrument "case studies" are still needed to improve the statistics.

In studying this particular event, a number of fortunate circumstances allowed us to substantially avoid many of the problems listed above.

Firstly the event shows a distinct positive excursion in the IMF $B_{z}$ component with no significant changes in the solar wind plasma pressure.

Second, the Geotail satellite was observing interplanetary medium just in front of the bow shock, the propagation time being as small as about $5 \mathrm{~min}$. Still, this time was calculated by Eq. (1), which contains two unknown parameters, namely, the flow velocity in the magnetosheath and the $\mathrm{x}$ coordinate of the magnetopause. Because of the short duration of the positive $B_{z}$ impulse, even a small error of \pm 2 $3 \mathrm{~min}$ in the propagation time may be crucial for the identification of the interplanetary variation causing the ionospheric response. The situation gets less ambiguous when features in the ionospheric convection are taken into consideration. The green curves in Fig. $4 \mathrm{~b}$ suggest the observation of a half of the four-cell convection pattern, with two reverse cells at high latitudes (see sketch in Fig. 9a). As was shown experimentally by e.g. Huang et al. (2000), such reverse cells are typical for northward IMF conditions. In the case presented here, the upper green curve in Fig. $4 \mathrm{~b}$ indicates the pre-noon reverse cell, consistent with the positive IMF $B_{z}$ deflection.

Third, the DMSP F13 satellite crossed the TV camera field of view $10 \mathrm{~min}$ prior to $B_{z}$ turning northward. Three auroral arcs were observed at that time. The DMSP data revealed that these arcs were embedded in the low latitude boundary layer. Hence, the open/closed field line boundary (OCFLB) was either poleward of the arc system or coincident with the most poleward arc. After the satellite crossing, we consider the arcs as an indicator of the $l l b l$ location. During the interval of positive $B_{z}$, the most poleward arc moved to the north. We then conclude that the $B_{z}$ turning caused the OCFLB to shift northward. This conclusion also agrees with the result of Chisham et al. (2004), showing the location of the merging line between the focii of the two reversed cells (i.e. poleward of the auroras shown in Fig. 4b).

Fourth, an important issue of a multi-instrument study is the correct location of different measurements. In the present study, for a correct mapping of the optical observations we estimated the altitude of auroras using DMSP electron precipitation data. The altitudes of the arcs could vary after the satellite pass, however the most important arcs A and
$\mathrm{B}$ are located close to zenith of the TV camera (within $30^{\circ}$ of zenith). In this case, a height uncertainty even as large as $60 \mathrm{~km}$ would yield a location error of the order of $35 \mathrm{~km}$ which is comparable with the spatial resolution of the HF radars. For a correct mapping of the HANK radar data, we applied a ray-tracing procedure which utilizes the elevation angle of arrival of the radar signals and the Troms $\varnothing$ dynasonde ionospheric plasma density profile (see also Sect. 2.3 above).

\subsection{Interpretation of the observations}

The sequence of events associated with a positive impulse in the IMF $B_{z}$ component is described which, as detailed above, is consistent with the concept of magnetosheath plasma capture during reconnection under northward IMF $B_{z}$ conditions. The IMF turning from the $\mathrm{XY}$ to $\mathrm{XZ}$ plane provides favorable conditions for reconnection near the noon meridian. The merging line (i.e. the open-closed field line boundary) appears at higher latitude compared to its previous position under southward IMF. Reconnected beyond the cusp (see sketch in Fig. 9b), the newly closed flux tubes in the pre-noon sector drift toward the Earth and dawnward. In general, this is consistent with the result of Watanabe et al. (2006) who showed that equatorward of the polar cap boundary, magnetosheath-like ions drifted from noon toward the flank. Those authors supposed that these ions were of magnetosheath origin and that they entered the closed region of the magnetosphere via reconnection. In Fig. $9 \mathrm{~b}$ the magnetosheath ions are shown as a grey area in the equatorial part of the flux tubes. Figure 7 suggests that in the event studied here the penetration of magnetosheath plasma occurred between arcs B and C, causing a poleward expansion of the $l l b l$ and the embedded $\operatorname{arcs} \mathrm{A}$ and B. The captured anisotropic plasma generates the ion-cyclotron Alfvén waves which propagate along magnetic field lines to the ionosphere (red arrows in Fig. 9b) and produce magnetic activity in the $0.1-3.0 \mathrm{~Hz}$ frequency band. This magnetic activity is observed at the magnetic observatory nearest to the footprint. The wave turbulence is associated with a fluctuating electric field in the ionosphere, which may cause anomalous echoes and a broad Doppler spectrum in the HANK radar data.

Such an interpretation is based on the coincidence of successful observations made by several instruments. At some points, these results may seem to contradict to the most widespread view on the relationship between the dayside auroras and radar backscatter.

Firstly, poleward moving auroral forms (PMAFs) observed near noon are frequently interpreted as cusp auroras. However, in the present case the PMAFs were located in the region of closed $l l b l$. Thus, in general, the near-noon PMAFs cannot necessarily be considered as indicators of the cusp.

Second, the PMAFs are frequently interpreted as ionospheric manifestation of sporadic reconnection. In the absence of other data, the arc B might have also been 
Table 1. Comparison of the interpretation of the event under study with widely-used interpretations.

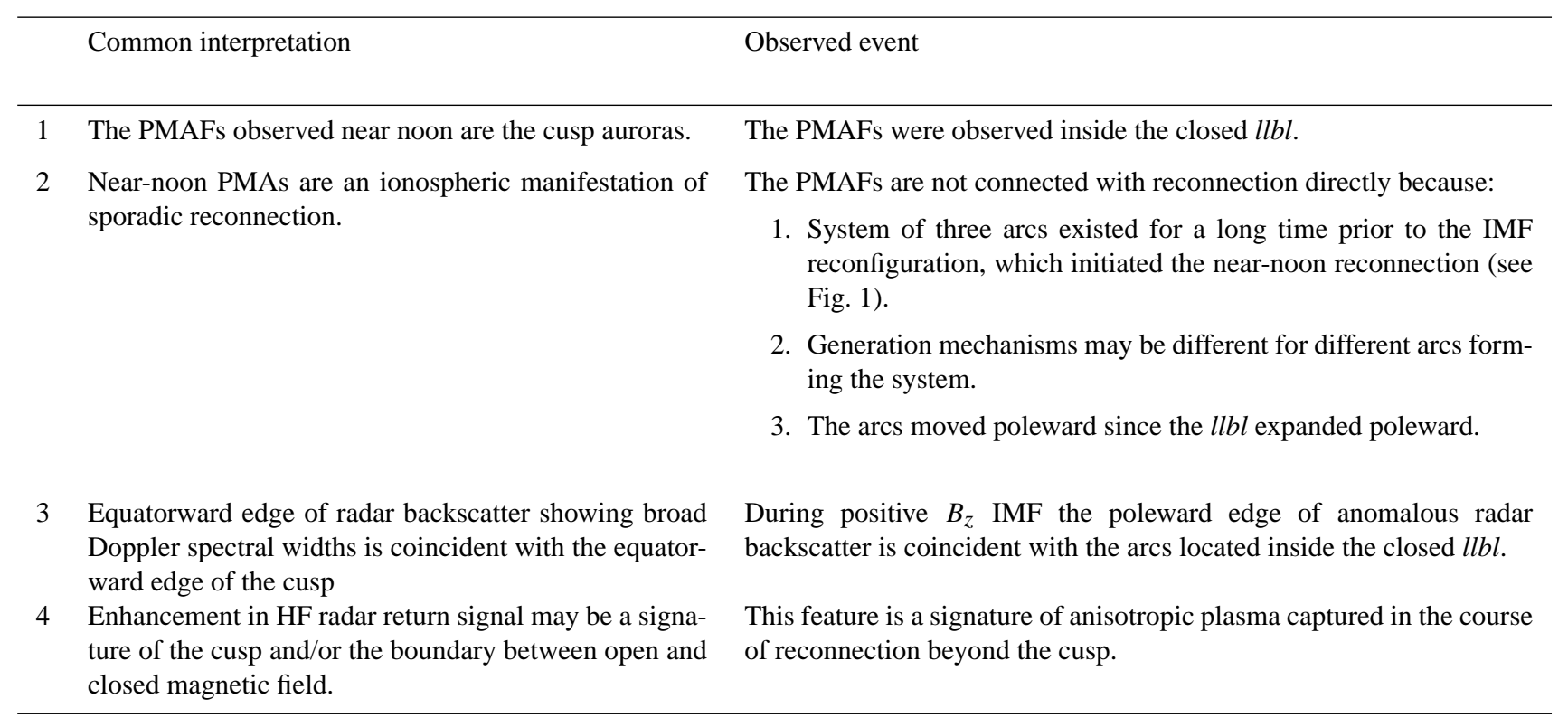

interpreted in this way. However, we have shown that there were three stable arcs associated with the closed $l l b l$. Their poleward motion corresponds to the poleward expansion of the $l l b l$ caused by the IMF $B_{z}$ turning northward. Actually, the reconnection is not the only mechanism for dayside poleward moving auroras. It has been shown that in some cases the PMAFs can be caused by other reasons, e.g., by field line resonance (Kozlovsky and Kangas, 2002), interchange or interchange-like instabilities (Lyatsky and Sibeck, 1997; Kozlovsky et al., 2003), the Kelvin-Helmholtz instability (Farrugia et al., 1994) or even auroral activity in the night side (Shiokava et al., 1997; Safargaleev et al., 2003).

Third, in many cases, it was found that the equatorward edge of radar backscatter showing broad Doppler spectral widths is coincident with the equatorward edge of the cusp (e.g. Yeoman et al., 1997). After this finding, the broad spectrum is frequently interpreted as a signature of the cusp. However, we have shown that during positive IMF $B_{z}$ the region of broad spectral width backscatter may be located inside the closed $l l b l$.

Fourth, an enhancement in the HF radar return signal was suggested to be a signature of the cusp and/or the boundary between open and closed magnetic field lines (Baker et al., 1995). We have shown that not only the cusp and open/closed boundary but also the closed llbl during northward IMF can be associated with the ionospheric turbulence causing radar backscatter. In particular, the data presented here show that a spatially isolated noise enhancement in the Pc1 frequency band occurs simultaneously with the anomalous radar backscatter. This can clarify the nature of the large spectral width in radar returns observed in limited areas, which is still a point of great debate (Wright et al., 2004).
The discrepancies between the features revealed in the event studied here and the most common interpretations are summarized in Table 1. This is an important issue of the present study. We emphasize that owing to a variety of interplanetary conditions and the complexity of magnetospheric dynamics, application of commonly accepted views to a particular event may lead to an erroneous interpretation. For example, in the absence of reliable IMF, plasma flow, and precipitation data, one could interpret the optical and CUTLASS data shown in Fig. 7 as a typical PMAF event initiated by cusp reconnection driven by southward IMF, which is actually not correct in the present case. Thus, careful study of the interplanetary conditions, ionospheric plasma flows, and precipitation data is necessary for a correct interpretation of dayside ionospheric phenomena.

\section{Conclusion}

We present a multi-instrument study of the ionospheric response to an isolated positive excursion in the IMF $B_{z}$ component. The observations were made in the near-noon (11:00 MLT) sector on Svalbard (at 75 MLAT). The data set includes auroral observations (ASC TV camera), convection patterns obtained from UHF EISCAT and HF CUTLASS radars, spectral width of the HF radar backscatter, particle precipitation and plasma flow data from the DMSP F13 satellite, Pc1 pulsations observed by induction magnetometers, and solar wind parameters measured by the Geotail satellite just in front of the magnetosphere. Careful collocation of all observations has been made. In particular, the heights of auroral luminosity were derived from the DMSP precipitation 
data, and the HF radar backscatter was located by a raytracing procedure utilizing the elevation angle of arrival of the radar signals and the ionospheric plasma density inferred from TRO dynasonde measurements.

Just prior to the IMF northward turning, three auroral arcs, $\mathrm{A}, \mathrm{B}$, and $\mathrm{C}$ existed at the poleward boundary of the closed $l l b l$, inside the $l l b l$, and in the equatorward part of the $l l b l$, respectively. The northward IMF turning was accompanied by the enhanced HF radar returns with a broad Doppler spectrum. The dynamics of the area of enhanced radar returns suggests that the poleward displacement of arcs A and B was caused by the development of that area toward the morning hours. The captured anisotropic plasma generates ioncyclotron Alfvén waves propagating along magnetic field lines to the ionosphere. At the magnetic observatory located near the footprints of these lines, an enhancement of magnetic activity in the $0.1-3.0 \mathrm{~Hz}$ frequency band is observed. The wave turbulence in the ionosphere may also be a reason for anomalous echoes in the HANK radar data.

We discuss possible interpretation errors which may be caused by limited observational data. In particular, it is shown that in the absence of reliable IMF, plasma flow, and precipitation data, one could interpret the optical and CUTLASS data as a typical PMAF event generated by cusp reconnection driven by southward IMF, whereas the more complete data set is consistent with the ionospheric response to the IMF turning northward.

Finally, we have shown that the appearance of anomalous radar backscatter correlates well with ULF enhancement at the nearest magnetic observatory. The absence of the signal at remote magnetic observatories excludes ionospheric waveguide propagation and, hence, indicates a local generation of the Pc1 turbulence collocated with the radar backscatter. This finding may be useful for further clarification of the nature of large spectral width radar returns.

Acknowledgements. GEOTAIL magnetic field and plasma data were provided by T. Nagai and H. Hayakawa, T. Mukai through DARTS at the Institute of Space and Astronautical Science (ISAS) in Japan. We would like to acknowledge the Radio and Space Plasma Physics Group of the University of Leicester, UK, for scientific input and data provision during the course of this study. We are indebted to the Director and staff of EISCAT for operating the facility and supplying the data. We thank the Finnish Meteorological Institute and other institutes who maintain the IMAGE magnetometer array. The Finnish pulsation magnetometer chain is operated by Sodankylä Geophysical Observatory. The DMSP particles detectors were designed by D.Hardy (AFRL), and data obtained from JHL/APL. The HER magnetic data are from the Kyoto World Data Center C-2 in Kyoto, Japan. We gratefully acknowledge the Center for Space Sciences at the University of Texas at Dallas and the U.S. Air Force for providing the DMSP thermal plasma data. We thank R. Kuula and J. Jussila at Space Research Group of the Oulu University for the EISCAT data analysis and assistance in optical data processing, respectively. The Academy of Finland supported work of V. Safargaleev and A. Kotikov (project 214621) and A. Kozlovsky and T. Turunen (project 205964). The work of V. Safargaleev and
T. Sergeinko was partially supported by the Nordic Council of Ministers (grant 087043-60105).

Topical Editor M. Pinnock thanks P. T. Newell and another anonymous referee for their help in evaluating this paper.

\section{References}

Anderson, B. J. and Fuselier, S. A.: Magnetic pulsations from 0.1 to $4.0 \mathrm{~Hz}$ and associated plasma properties in the Earth's subsolar magnetosheath and plasma depletion layer, J. Geophys. Res., 98, 1461-1479, 1993.

André, R., Pinnock, M., and Rodger, A. S.: Identification of the low-latitude cusp by Super Dual Auroral Radar Network radars: A physical explanation for the empirically derived signatures, J. Geophys. Res., 105, 27 081-27 094, 2000.

Baker, K. B., Dudeney, J. R., Greenwald, R. A., Pinnock, M., Newell, P. T., Rodger, A. S., Mattin, N., and Meng, C.-I.: HF radar signatures of the cusp and low-latitude boundary layer, J. Geophys. Res., 100, 7671-7695, 1995.

Chisham, G., Freeman, M. P., Coleman, I. J., Pinnock, M., Hairston, M. R., Lester, M., and Sofko, G.: Measuring the dayside reconnection rate during an interval of due northward interplanetary magnetic field, Ann. Geophys., 22, 4243-4258, 2004, http://www.ann-geophys.net/22/4243/2004/.

Chisham, G., Lester, M., Milan, S. E., Freeman, M. P., Bristow, W. A., Grocott, A., McWilliams, K. A., Ruohoniemi, J. M., Yeoman, T. K., Dyson, P. L., Greenwald, R. A., Kikuchi, T., Pinnock, M., Rash, J. P. S., Sato, N., Sofko, G. J., Villain, J.-P., and Walker, A. D. M.: A decade of the Super Dual Auroral Radar Network (SuperDARN): scientific achievements, new techniques and future directions, Surv. Geophys., 28, 33-109, 2007.

Chisham, G., Pinnock, M., and Rodger, A. S.: The response of the HF radar spectral width boundary to a switch in the IMF By direction: Ionospheric consequences of transient dayside reconnection?, J. Geophys. Res., 106, 191-202, 2001.

Denton, R. and Vetoulis, G.: Global poloidal mode, J. Geophys. Res., 103, 6729-6739, 1998.

Farrugia, C. J., Gratton, F. T., Bender, L., Biernat, H. K., Erkaev, N. V., Quinn, J. M., Torbert, R. B., and Dennisenko, V.: Charts of joint Kelvin-Helmholtz and Rayleigh-Taylor instabilites at the dayside magnetopause for strongly northward interplanetary magnetic field, J. Geophys. Res., 103, 6703-6728, 1998.

Farrugia, C. J., Sandholt, P. E., and Burlaga, L. F.: Auroral activity associated with Kelvin-Helmholtz instability at the inner edge of the low-latitude boundary layer, J. Geophys. Res., 99, $19403-$ 19411, 1994.

Fasel., G. J.: Dayside poleward moving auroral forms: A statistical study, J. Geophys. Res., 100, 11 891-11 905, 1995.

Freeman, M. P., Farrugia, C. J., Cowley, S. W. H., and Etemadi, A.: The response of dayside ionospheric convection to the Ycomponent of the magnetosheath magnetic field: A case study, Planet. Space Sci., 38, 13-41, 1990.

Huang, C.-S., André, D. A., Sofko, G. J., and Kustov, A. V.: Super Dual Auroral Radar Network observations of ionospheric multicell convection during northward interplanetary magnetic field, J. Geophys. Res, 105, 7419-7428, 2000.

Kangas, J., Guglielmi, A., and Pokhotelov. O.: Morphology and physics of short-period magnetic pulsations, Space Sci. Rev., 83, 
435-512, 1998.

Kozlovsky, A. and Kangas, J.: Motion and origin of noon high-latitude poleward moving auroral arcs on closed magnetic field lines, J. Geophys. Res., 107, SMP 1-1, doi:10.1029/2001JA900145, 2002.

Kozlovsky, A. E., Safargaleev, V. V., Jussila, J., and Koustov, A. V.: Pre-noon high latitude auroral arcs as a manifestation of the interchange instability, Ann. Geophys., 21, 2303-2314, 2003, http://www.ann-geophys.net/21/2303/2003/.

Kozlovsky, A., Safargaleev, V., Ostgaard, N., Koustov, A., Jussil, J., and Roldugin, A.: On the motion of dayside auroras caused by a solar wind pressure pulse, Ann. Geophys., 23, 509-521, 2005, http://www.ann-geophys.net/23/509/2005/.

Lockwood, M.: Identifying the open-closed field line boundary, in: Polar Cap Boundary Phenomena, edited by: Moen, J., Egeland, A., and Lockwood, M., NATO Advanced Study Institute Series, Kluwer Academic Press, Dordrecht, The Netherlands, 509, 73 90, 1998.

Lockwood, M., Sandholt, P. E., Cowley, S. W. H., and Oguti, T.: Interplanetary magnetic field control of the dayside auroral activity and the transfer of momentum across the dayside magnetopause, Planet. Space. Sci., 37, 1347-1365, 1989.

Lyatsky, W. and Sibeck, D.: Central plasma sheet disruption and the formation of dayside poleward moving auroral events, J. Geophys. Res., 102, 17 625-17 630, 1997.

Milan, S. E., Lester, M., Cowley, S. W. H., Moen, J., Sandholt, P. E., and Owen, C. J.: Meridian-scanning photometer, coherent HF radar, and magnetometer observations of the cusp: a case study, Ann. Geophys., 17, 159-172, 1999, http://www.ann-geophys.net/17/159/1999/.

Moen, J., Carlson, C., Milan, S. E., Shumilov, N., Lybekk, B., Sandholt, P. E., and Lester, M.: On the collocation between dayside auroral activity and coherent HF radar backscatter, Ann. Geophys., 18, 1531-1549, 2001, http://www.ann-geophys.net/18/1531/2001/.

Newell, P. T., Sanchez, E. R., Meng, C.-I., Burke, W. J., Greenspan, M. E., and Clauer, C. R.: The low latitude boundary layer and the boundary plasma sheet at low altitude: prenoon precipitation regions and convection reversal boundaries, J. Geophys. Res., 96, $21013-21023,1991$.

Newell, P. T. and Meng, C.-I.: Mapping the dayside ionosphere to the magnetosphere according to particle precipitation characteristics, Geophys. Res. Lett., 19, 609-612, 1992.

Newell, P. T., Ruohoniemi, J. M., and Meng, C.-I.: Maps of precipitation by source region, binned by IMF, with inertial convection streamlines, J. Geophys. Res., 109, A10206, doi:10.1029/2004JA010499, 2004.

Onsager, T. D., Scudder, J. D., Lockwood, M., and Russell, C. T.: Reconnection at the high-latitude magnetopause during northward interplanetary magnetic field conditions, J. Geophys Res., 106, 25 467-25 488, 2001.

Pinnock, M., Rodger, A. S., Dudeney, J. R., Rich, F., and Baker, K. B.: High spatial and temporal resolution observations of the ionospheric cusps, Ann. Geophys., 13, 919-925, 1995, http://www.ann-geophys.net/13/919/1995/.

Pryse, S. E., Sims, R. W., Moen, J., and Oksavik, K.: Ionospheric signatures of the low-latitude boundary layer under conditions of northward IMF and small clock angle, Ann. Geophys., 24, 21692178,2006 http://www.ann-geophys.net/24/2169/2006/.

Ridley, A. J.: Estimations of the uncertainty in timing the relationship between magnetospheric and solar wind processes, J. Atmos. Solar-Terr. Phys., 62, 757-771, 2000.

Safargaleev, V. V. and Lyatsky, W. B.: Flute instability of the magnetopause in the presence of the magnetic barrier (Engl. transl.), Geomagn. Aeronomy, 31, 354-359, 1991.

Safargaleev, V. V., Serebryanskaya, A. V., Koustov, A. V., Lester, M., Pchelkina, E. V., and Vasilyev, A. N.: A possible origin of dayside Pc1 magnetic pulsations observed at high latitudes, Ann. Geophys., 22, 2997-3008, 2004,

http://www.ann-geophys.net/22/2997/2004/.

Sandholt, P. E., Deehr, S., Egeland, A., Lybekk, B., Viereck, R., and Romick, G. J.: Signatures in the dayside aurora of plasma transfer from the magnetosheath, J. Geophys. Res., 91, 10063 $10079,1986$.

Sandholt, P. E., Farrugia, C. J., Cowley, S. W. H., Deing, W. F., Lester, M., Moen, J., and Lybekk, B.: Capture of magnetosheath plasma by the magnetosphere during northward IMF, Geophys. Res. Lett., 26, 2833-2836, 1999.

Sandholt, P. E., Farrugia, C. J., Cowley, S. W. H., Lester, M., Deing, W. F., Cerisier, J.-C., Milan, S. E., Moen, J., Trondsen, E., and Lybekk, B.: Dynamic cusp aurora and associated pulsed reverse convection during northward interplanetary magnetic field, J. Geophys. Res., 105, 12 869-12 894, 2000.

Sandholt, P. E., Farrugia, C. J., Cowley, S. W. H., Lester, M., and Cerisier, J.-C.: Excitation of transient lobe cell convection and auroral arc at the cusp poleward boundary during a transition of the interplanetary magnetic field from south to north, Ann. Geophys., 19, 487-493, 2001, http://www.ann-geophys.net/19/487/2001/.

Sergienko, T. I. and Ivanov, V. E.: A new approach to calculate the excitation of atmospheric gases by auroral electron impact, Ann. Geophys., 11, 717-727, 1993, http://www.ann-geophys.net/11/717/1993/.

Song, P. and Russell, C. T.: Model of the formation of the lowlatitude boundary layer for strongly northward interplanetary magnetic field, J. Geophys. Res., 97, 1411-1420, 1992.

Thorolfsson, A., Cerisier, J.-C., Lockwood, M., Sandholt, P. E., Senior, C., and Lester, M.: Simultaneous optical and radar signatures of poleward-moving auroral forms, Ann. Geophys., 18, 1054-1066, 2000, http://www.ann-geophys.net/18/1054/2000/.

Villain, J.-P., Greenwald, R. A., and Vickrey, J. F.: HF ray tracing at high latitudes using measured electron density distribution, Radio Sci., 19, 359-374, 1984.

Wright, D. M., Yeoman, T. K., and Woodfield, E. E.: The effects of high frequency ULF wave activity on the spectral characteristics of coherent HF radar returns: a case study, Ann. Geophys., 22, 1843-1849, 2004, http://www.ann-geophys.net/22/1843/2004/.

Yeoman, T. K., Lester, M., Cowley, S. W. H., Milan, S. E., Moen, J., and Sandholt, P. E.: Simultaneous observation of the cusp in optical, DMSP and HF radar data, Geophys. Res. Lett., 24, 2251-2254, 1997.

Watanabe, M., Sofko, G. J., André, D. A., Ruohoniemi, J. M., Hairston, M. R., and Kabin, K.: Ionospheric signatures of internal reconnection for northward interplanetary magnetic field: Observation of "reciprocal cells" and magnetosheath ion precipitation, J. Geophys. Res., 111, A06201, doi:10.1029/2005JA011446, 2006. 